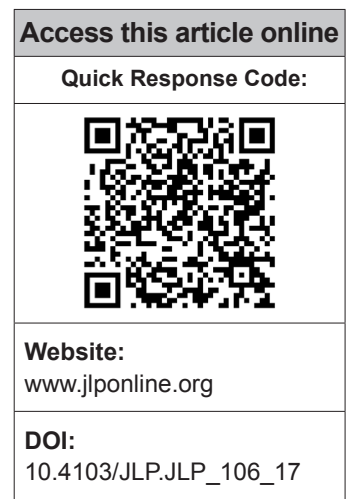

Departments of Pathology,

${ }^{1}$ General Surgery,

2Surgical Oncology and ${ }^{3}$ Endocrinology, Sri

Venkateswara Institute of Medical Sciences, Tirupati,

Andhra Pradesh, India

Address for correspondence:

Dr. Rukmangadha Nandyala,

Department of Pathology,

Sri Venkateswara Institute of Medical

Sciences, Tirupati, Andhra Pradesh, India. E-mail: nrukmangadha1@ rediffmail.com

Submission: 17-06-2017 Accepted: 19-11-2017

\title{
Value of cytokeratin-19, Hector Battifora mesothelial-1 and galectin-3 immunostaining in the diagnosis of thyroid neoplasms
}

\author{
Rajasekhar Sanuvada, Rukmangadha Nandyala, Amit Kumar Chowhan, \\ Phaneendra Bobbidi, Mutheeswariah Yootla ${ }^{1}$, Narendra Hulikal ${ }^{2}$, Alok Sachan ${ }^{3}$
}

\begin{abstract}
:
BACKGROUND: Diagnosis of types and aggressiveness of thyroid cancers is difficult. The "gold standard" in diagnosis is using routine hematoxylin and eosin staining. Several markers have been investigated for differentiating them among which cytokeratin-19 (CK-19), Hector Battifora mesothelial cell (HBME-1), and galectin-3 are found to be most commonly used. Most studies have evaluated the single expression of markers in various thyroid lesions.
\end{abstract}

AIMS AND OBJECTIVES: To know the value of immunohistochemical expression of CK-19, HBME-1, and galectin-3 in diagnosing thyroid neoplasms. To study the expression and compare the results of HBME-1, CK-19, and galectin-3 immunohistochemical markers in histopathologically diagnosed malignant lesions and nonmalignant lesions and demonstrate their usefulness in differentiating them.

MATERIALS AND METHODS: A prospective study was carried out on thyroidectomy specimens sent in 10\% bufferedformalinto DepartmentofPathology, SVIMS, Tirupati, from May2013to August2014. Sensitivity and specificity for each marker and their combination in diagnosis were calculated.

RESULTS: Among 120 cases, nonmalignant lesions were 70 (58.33\%) and malignant lesions 50 (41.67\%). Among nonmalignant lesions, 65 (93\%) were adenomatous goiter and $5(7 \%)$ were follicular adenomas. In malignant lesions, $48(96 \%)$ were papillary carcinoma and $1(2 \%)$ each of follicular carcinoma and anaplastic carcinoma. Among papillary carcinomas, classical were26(54.16\%) followed by 17 follicularvariant (35.41\%). Galectin-3 had highest sensitivity of $90 \%$ and HBME- 1 had highest specificity of $97.14 \%$.

CONCLUSIONS: Panel of HBME-1+ galectin-3 or CK-19, HBME-1, and galectin-3 increase the accuracy of diagnosis in histopathologically difficult cases.

Key words:

Cytokeratin-19, galectin-3, Hector Battifora mesothelial-1, malignant, nonmalignant, thyroid

\section{Introduction}

$\mathrm{D}$ espite great advances in the understanding of thyroid tumors, there are problems and unanswered questions. The great variety of types and the wide range of aggressiveness of thyroid cancers continue to complicate both diagnosis and management. It should be stressed that it is difficult clinically, and at times pathologically, to distinguish true neoplasm

This is an open access article distributed under the terms of the Creative Commons Attribution-NonCommercial-ShareAlike 3.0 License, which allows others to remix, tweak, and build upon the work non-commercially, as long as the author is credited and the new creations are licensed under the identical terms.

For reprints contact: reprints@medknow.com from a nodule of adenomatous goiter. The "gold standard" in diagnosis of thyroid nodules is pathologic evaluation using routine hematoxylin and eosin $(\mathrm{H}$ and $\mathrm{E})$ staining. However, the morphologic overlap between follicular lesions, especially the follicular variant of papillary carcinoma (FVPC) is common which is characterized by an almost exclusive follicular growth pattern and a set of nuclear features identical to those of the classic type of papillary carcinoma of thyroid (PCT). ${ }^{[1]}$

How to cite this article: Sanuvada R, Nandyala R, Chowhan AK, Bobbidi P, Yootla M, Hulikal N, et al. Value of cytokeratin-19, Hector Battifora mesothelial-1 and galectin-3 immunostaining in the diagnosis of thyroid neoplasms. J Lab Physicians 2018;10:200-7. 
Diagnostic dilemma may arise when an encapsulated nodule with a follicular pattern of growth exhibits clear nuclei with grooves and so distinguishing follicular adenoma (FA) from encapsulated FVPCT becomes difficult. There are several other thyroid lesions that may contain papillary processes with nuclear features, which pose diagnostic difficulties with PCT. Multinodular goiter with delicate papillary budding and focal nuclear clearing may be confused with PCT.

Several markers have been investigated for differentiating them. Among the markers tested cytokeratin-19 (CK-19), Hector Battifora Mesothelial (HBME-1) cell, and galectin-3 are found to be most commonly used. ${ }^{[1]}$ Most studies have evaluated the single expression of markers in various thyroid lesions, and a few reports have studied the combined expression of markers. The present study is to know the value of these three markers when used as panel for precise diagnosis of thyroid neoplasms.

In our study, we attempt to know the value of immunohistochemical expression of CK-19, HBME-1, and galectin-3 in the diagnosis of thyroid neoplasms, by demonstrating the expression of HBME-1, CK-19, and galectin-3 immunohistochemical markers in histopathologically diagnosed malignant and nonmalignant lesions. The expression of these three markers in malignant and nonmalignant lesions and their usefulness in differentiating them will be assessed.

\section{Materials and Methods}

After obtaining Ethical Committee approval, this prospective study on thyroid lesions was carried out in the Department of Pathology, over 1 year and 4 months from May 2013 to August 2014. All the thyroidectomy specimens (total, subtotal, and hemithyroidectomy) sent in $10 \%$ buffered formalin were included in the study. Thyroidectomy specimens from patients with inflammatory thyroid conditions such as granulomatous thyroiditis and Hashimoto thyroiditis and with metastatic cancers in thyroid were excluded. In the present study, out of a total of 129 thyroidectomy specimens received, 9 were excluded from the study (8 Hashimoto's thyroiditis and 1 case of metastasis). Specimens included in the study were 120 thyroidectomy specimens which were subjected to histopathological examination under the light microscope using routine hematoxylin and eosin ( $\mathrm{H}$ and $\mathrm{E})$ stain which is taken as the gold standard.

The diagnosis of FA was made based on the presence of encapsulated mass with homogenous follicular proliferation, lack of PCT nuclear features, and absence of vascular and/or capsular invasion. The diagnosis of classic PCT was based on the presence of papillary structures with fibrovascular cores and specific nuclear features widely known as typical of papillary carcinoma. The FVPC was diagnosed based on the presence of follicular growth pattern with classic PCT-type nuclear features in at least several areas of the tumor. Papillary microcarcinoma is defined as a papillary carcinoma measuring $1 \mathrm{~cm}$ or less in diameter. Hurthle cell/oncocytic (oxyphilic) variant, the nuclear features remain those of papillary carcinoma but the cytoplasm is abundant and has a granular oxyphilic quality. The pattern of growth may be papillary or follicular, and the tumor may be encapsulated or invasive. Poorly differentiated (insular) carcinoma shows evidence of follicular differentiation. Microscopically, the tumor consists of sheets, trabeculae, or nests (insula) of cells with central rounded nuclei. Follicular carcinoma was diagnosed based on the presence of follicular proliferation with complete thick capsule and full capsular penetration and/or vascular invasion, and atypical hyperchromatic nuclei that lacked features of PCT nuclei.

\section{Immunohistochemistry}

All the 120 samples (70 nonmalignant lesions and 50 malignant lesions) were subjected to immunohistochemical staining with CK-19, HBME-1, and galectin-3 antibodies. The sections were deparaffinized in xylene and rehydrated through absolute alcohol. Antigen retrieval in citrate buffer ( $\mathrm{pH} 9 \mathrm{Lab}$ vision cat\#AP9003) was used after the sections were treated in a microwave at $8 \mathrm{~W}$ for $5-6 \mathrm{~min}$, then at $3 \mathrm{~W}$ for $10 \mathrm{~min}$, and the sections were then left to cool for $20 \mathrm{~min}$. Peroxidase and protein blocks were done. After that the slides were incubated overnight with the primary antibodies at room temperature using CK-19 - Prediluted mouse monoclonal antibody, Biogenix company. HBME1 - Prediluted mouse monoantibody, Cell Marque company. Galectin-3 - mouse monoclonal antibody, Cell Marque company followed by rinsing in PBS (phosphate buffered saline, $\mathrm{pH}$ 7.6). This was followed by the secondary biotin-conjugated antibody for $1 \mathrm{~h}$ and finally the peroxidase-conjugated streptavidin for another hour. Diaminobenzidine tetrachloride was added for $25 \mathrm{~min}$, and then counterstained in hematoxylin, followed by dehydration, clearing, and mounting. Positive control sections were prepared from prostatic adenocarcinoma for CK19 and papillary thyroid carcinoma for HBME-1 and galectin-3 (as per manufacturer instructions). For galectin-3, macrophages and blood vessels also served as internal control. Negative controls were done by excluding primary antibody and its replacement with PBS.

\section{Immunohistochemical evaluation}

HBME-1 was positive predominantly in the cell membrane and cytoplasm. CK-19 showed cytoplasmic positivity. Galectin-3 showed cytoplasmic and nuclear 
positivity. Staining of the follicular colloid in the absence of staining of the follicular epithelium and/or cytoplasm was considered nonspecific and negative. The intensity of staining of immunoreactive cells and their $\%$ distribution pattern was evaluated [Table 1]. ${ }^{[2]}$

\section{Statistical analysis}

Data were entered in Microsoft Excel 2007 Spreadsheet (Microsoft Corp, Redmond, WA, USA). The categorical variables were expressed as proportions, and continuous proportions were expressed as mean \pm standard deviation. Associations were assessed between intensity of staining of immunoreactive cells and percentage distribution pattern for all the cases studied using $2 \times 2$ contingency table analysis and Chi-square test was used where appropriate.

Total score was made by addition of individual scores of percentage distribution of cells and intensity and was divided into two groups, that is, $0-3$ and $4-7$. By comparing the values in these two groups for malignant and nonmalignant lesions, sensitivity, specificity, positive predictive value (PPV), and negative predictive value (NPV) were calculated.

\section{Results}

Of the 120 cases, 70 cases were nonmalignant lesions (58.33\%) with 65 cases $(93 \%)$ being adenomatous goiter and $5(7 \%)$ being FA. The remaining 50 cases were malignant lesions (41.67\%), with 48 cases (96\%) being papillary carcinoma and 1 (2\%) each of follicular carcinoma and anaplastic carcinoma. Among the papillary carcinomas, classical PCT (26 cases, 54.16\%) was the most common type followed by FVPCT (17 cases, $35.41 \%)$.

\section{Immunohistochemical findings}

The positivity, negativity, percentage distribution of cells, and intensity of CK19, HBME-1, and galectin-3 in all thyroid lesions were recorded [Table 2].

\section{Immunohistochemical CK19 expression in thyroid lesions}

Malignant lesions had higher CK19 expression when compared to nonmalignant lesions [Table 3].

Table 1: Scoring for percentage of cells stained and for intensity of staining

\begin{tabular}{lclc}
\hline $\begin{array}{l}\text { Percentage of cells } \\
\text { stained }\end{array}$ & Reaction & $\begin{array}{l}\text { Intensity of } \\
\text { staining }\end{array}$ & $\begin{array}{c}\text { Intensity } \\
\text { score }\end{array}$ \\
\hline 0 & No visible reaction & No staining & 0 \\
$1-5$ & $1+$ & Weak & 1 \\
$>5-25$ & $2+$ & Moderate & 2 \\
$>25-75$ & $3+$ & Strong & 3 \\
$>75$ & $4+$ & - & - \\
\hline
\end{tabular}

When malignant and nonmalignant lesions werecompared in terms of percentage of staining, $3+$ or $4+$ staining was found in $80 \%$ of malignant lesions [Figures $1 \mathrm{~b}$ and $2 \mathrm{~b}$ ] and negative or $1+$ or $2+$ in $98.57 \%$ of nonmalignant lesions [Figures $3 \mathrm{~b}$ and $4 \mathrm{~b}$ ]. Malignant and nonmalignant lesions were compared in terms of intensity of staining. $2+$ or $3+$ staining was found in $84 \%$ of malignant lesions [Figures $1 \mathrm{~b}$ and $2 \mathrm{~b}$ ] and negative or $1+$ in $87.14 \%$ of nonmalignant lesions [Figures $3 \mathrm{~b}$ and $4 \mathrm{~b}$ ].

\section{Immunohistochemical Hector Battifora} mesothelial-1 expression in thyroid lesions

Malignant lesions had higher HBME-1 expression when compared to nonmalignant lesions [Table 4].

When malignantand nonmalignant lesions werecompared in terms of percentage of staining, $3+$ or $4+$ staining was found in $80 \%$ of malignant lesions [Figures 1c and Figures 2d] and negative or $1+$ or $2+$ in $97.14 \%$ of nonmalignant lesions [Figures $3 \mathrm{c}$ and $4 \mathrm{c}$ ]. Malignant and nonmalignant lesions were compared in terms of intensity of staining, $2+$ or $3+$ staining was found in $80 \%$ of malignant lesions [Figures $1 \mathrm{c}$ and $2 \mathrm{~d}$ ] and negative or $1+$ in $92.85 \%$ of nonmalignant lesions [Figures $3 c$ and $4 c$ ].

\section{Immunohistochemical galectin-3 expression in thyroid lesions \\ Malignant lesions had higher galectin-3 expression when compared to nonmalignant lesions [Table 5].}

When malignant and nonmalignant lesions were compared in terms of percentage of staining, $3+$ or $4+$ staining was found in $86 \%$ of malignant lesions [Figures $1 \mathrm{~d}$ and $2 \mathrm{c}$ ] and negative or $1+$ or $2+$ in $91.42 \%$ of nonmalignant lesions [Figures $3 \mathrm{~d}$ and $4 \mathrm{~d}$ ]. Malignant and nonmalignant lesions were compared in terms of intensity of staining, $2+$ or $3+$ staining was found in $88 \%$ of malignant lesions [Figures 1d and 2c] and negative or 1+ in $84.28 \%$ of nonmalignant lesions [Figures $3 \mathrm{~d}$ and $4 \mathrm{~d}$ ].

\section{Sensitivity and specificity of immunohistochemical markers in thyroid lesions}

Galectin-3 was found to have highest sensitivity and HBME-1 was found to have the highest specificity. Either independently or a combination of markers, the sensitivity and specificity were similar [Table 6].

\section{Comparative studies}

The sensitivity, specificity, PPV, and NPV of the immunohistochemistry markers individually and in combination found in our study were compared with findings of other studies [Table 7].

\section{Discussion}

A common dilemma is encountered with tumors showing 
Table 2: Positivity of cytokeratin-19, Hector battifora mesothelial cell-1 and galectin-3 in malignant and nonmalignant thyroid lesions

\begin{tabular}{lcccc}
\hline Lesions & Total number of cases $(\boldsymbol{n})$ & CK-19 positive cases, $\boldsymbol{n}(\%)$ & HBME-1 positive cases, $\boldsymbol{n}(\%)$ & Galectin-3 positive cases, $\boldsymbol{n}(\%)$ \\
\hline Malignant & 50 & $45(90)$ & $44(88)$ & $48(96)$ \\
PCT & 48 & $45(93.75)$ & $44(91.66)$ & $47(97.91)$ \\
FC & 1 & 0 & 0 & 0 \\
AC & 1 & 0 & 0 & $1(100)$ \\
Nonmalignant & 70 & $44(62.85)$ & $24(34.28)$ & $45(64.28)$ \\
AG & 65 & $41(63.07)$ & $20(30.76)$ & $43(66.15)$ \\
FA & 5 & $3(60)$ & $4(80)$ & $2(40)$ \\
\hline
\end{tabular}

PCT = Papillary carcinoma of thyroid, $\mathrm{FC}=$ Follicular carcinoma, $\mathrm{AC}=$ Anaplastic carcinoma, $\mathrm{AG}=\mathrm{Adenomatous} \mathrm{goiter}, \mathrm{FA}=\mathrm{Follicular}$ adenoma, CK-19 = Cytokeratin-19, HBME-1 = Hector Battifora mesothelial cell-1

Table 3: Scores of different thyroid lesions in terms of percentage distribution and intensity for cytokeratin-19

\begin{tabular}{|c|c|c|c|c|c|c|c|c|c|}
\hline \multirow[t]{2}{*}{ Lesions } & \multirow[t]{2}{*}{ Total cases $(n)$} & \multirow[t]{2}{*}{ Negative/score $0(n)$} & \multicolumn{4}{|c|}{ Percentage distribution } & \multicolumn{3}{|c|}{ Intensity } \\
\hline & & & $1+$ & $2+$ & $3+$ & $4+$ & $1+$ & $2+$ & $3+$ \\
\hline$\overline{A G}$ & 65 & 24 & 31 & 9 & 1 & 0 & 33 & 8 & 0 \\
\hline FA & 5 & 2 & 2 & 1 & 0 & 0 & 2 & 1 & 0 \\
\hline Conventional PCT & 26 & 0 & 0 & 3 & 8 & 15 & 1 & 9 & 16 \\
\hline FVPCT & 17 & 2 & 0 & 1 & 11 & 3 & 1 & 7 & 7 \\
\hline НСРСТ & 3 & 1 & 1 & 0 & 1 & 0 & 1 & 1 & 0 \\
\hline $\begin{array}{l}\text { Microcarcinoma } \\
\text { PCT }\end{array}$ & 2 & 0 & 0 & 0 & 1 & 1 & 0 & 1 & 1 \\
\hline FC & 1 & 1 & 0 & 0 & 0 & 0 & 0 & 0 & 0 \\
\hline$A C$ & 1 & 1 & 0 & 0 & 0 & 0 & 0 & 0 & 0 \\
\hline
\end{tabular}

$\mathrm{AG}=$ Adenomatous goiter, $\mathrm{FA}=$ Follicular adenoma, $\mathrm{PCT}=$ Papillary carcinoma of thyroid, FVPCT $=$ Follicular variant of $\mathrm{PCT}$, HCPCT $=\mathrm{Hurthle}$ cell variant of $\mathrm{PCT}, \mathrm{FC}=$ Follicular carcinoma, $\mathrm{AC}=$ Anaplastic carcinoma

follicular growth pattern. The presence or absence of capsular and/or vascular invasion distinguishes benign from malignant follicular tumors, but identification of this finding can be challenging due to incomplete capsular invasion. Another situation encountered is when some of the nuclear features of PCT are present. In the absence of papillary architecture, distinguishing the FVPCs from cellular adenomatous goiter [Figure 4a] may be difficult. ${ }^{[3]}$ To overcome these diagnostic difficulties, investigators have done several studies over the past few years in finding immunohistochemical markers that help in establishing the diagnosis in such situations. ${ }^{[4,5]}$

In the present study of 120 cases, majority of the patients were in the third decade followed by fourth and second decades. Age of the patients ranged from 15 to 80 years, mean age being 41.3 years. This is in concordance with the study of Anidi et al. ${ }^{[6]}$ and Gitau ${ }^{[7]}$ Thyroid neoplasms are more common in females. In our study, 23 were male and 97 were female. Male:female ratio is 1:4.2 which is in accordance with literature. ${ }^{[8,9]}$ Of the 120 cases in the present study, $70(58.33 \%)$ were nonmalignant and $50(41.67 \%)$ were malignant, which is in accordance with majority of the studies which showed predominant benign lesions. ${ }^{[7-9]}$ Among nonmalignant lesions, adenomatous goiter is the most common (92.85\%) similar to the study of Gole. ${ }^{[10]}$ The other nonmalignant lesion was FA [Figure 3a], which constituted 7.15\%. In our study, papillary carcinoma [Figure 1a] is predominant among malignant thyroid neoplasms accounting to $96 \%$ similar to studies done by Gole et al. ${ }^{[10]}$ (92\%) and Anne Petal (90\%). Unlike our study, Thomas and Ogunbiyi ${ }^{[11]}$ 1995 showed low predominance, that is, $45.3 \%$ including Khan et al. (Rawalpindi) ${ }^{[12]} 1991-60 \%$, whereas Ahmad et al. (Saudi Arabia) ${ }^{[8]} 1992$ reported a predominance of $80 \%$. In our series, the highest prevalence of papillary carcinomas is observed in the third decade and is more common in females. Similar observations are seen in the studies of Ahmad et al..$^{[8]}$ and Gole ${ }^{[10]}$ et al. In the present study, classical papillary carcinoma is diagnosed in 26 cases (54.16\%). Among variants, FVPC thyroid [Figure 2a] is the most common (17 cases), other two variants were Hurthle cell variant (3 cases) and micropapillary carcinomas (2 cases). Only one case of follicular carcinoma is reported in our study and the incidence being $2 \%$ when compared to all malignant lesions. This is in contrast to majority of other studies such as Khan et al. ${ }^{[12]}(24 \%)$ and Woolner et al. ${ }^{[13]}(17.7 \%)$, in which a significantly higher percentage is reported. Incidence of anaplastic carcinoma in the present study is $2 \%$ ( 1 case), while Thomas and Ogunbiyi ${ }^{[11]}$ reported an incidence of $4.4 \%$.

CK-19: In 50 malignant cases, CK-19 have shown positivity in 45 cases (90\%) which is similar to the study done by Scognamiglio et al. ${ }^{[14]} 47$ cases $(82.45 \%)$. In 70 


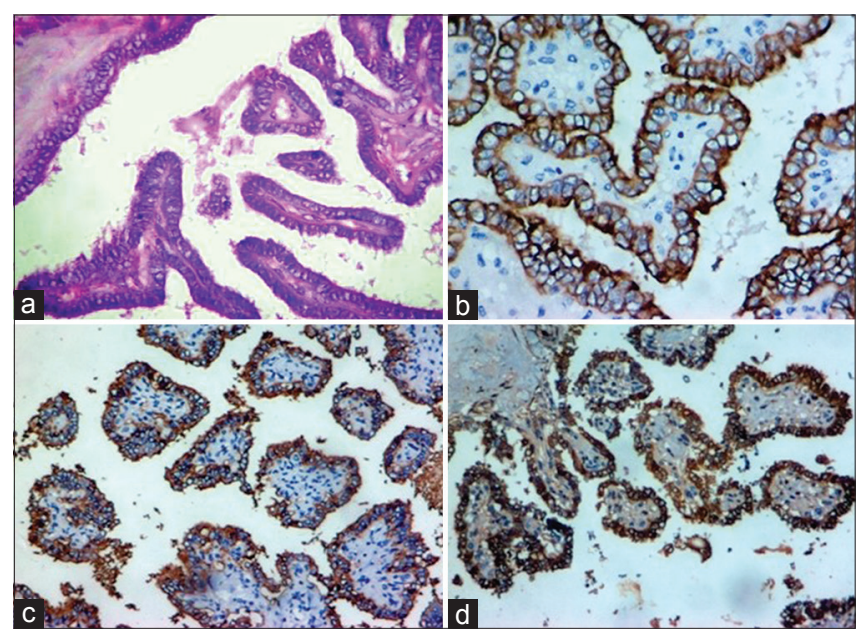

Figure 1: (a) Papillae with central fibrovascular core and nuclear features of papillary carcinoma $(\mathrm{H}$ and $\mathrm{E}, \times 10)$. (b) cytokeratin-19 showing diffuse intense cytoplasmic positivity (×20). (c) Hector Battifora mesothelial-1 showing membranous and cytoplasmic positivity (×20). (d) Galectin-3 showing cytoplasmic positivity $(\times 20)$

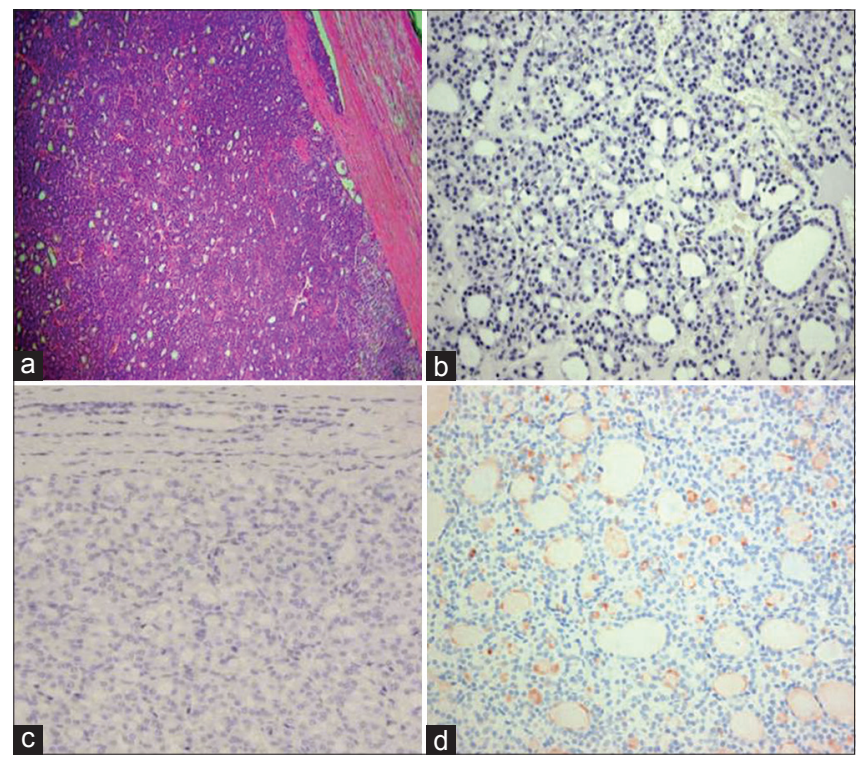

Figure 3: (a) Follicular adenoma with intact capsule ( $\mathrm{H}$ and $\mathrm{E}, \mathrm{x}$ ). (b) cytokeratin-19 showing negativity for follicular neoplastic cells $(\times 10)$. (c) Hector Battifora mesothelial-1 showing negativity for follicular neoplastic cells $(\times 10)$. (d) Galectin-3 showing negativity for follicular neoplastic cells but mild nonspecific positivity for colloid $(\times 4)$

nonmalignant cases, CK-19 is positive in 44 cases (62.85\%), which is less when compared to Scognamiglio et al. ${ }^{[14]}$ study (79.16\%). CK-19 showed positivity in 45 (93.75\%) of 48 papillary carcinoma cases, higher than that of de Matos et al. ${ }^{[2]}$ (72.6). It was negative for both follicular and anaplastic carcinoma cases. While de Matos et al. ${ }^{[2]}$ study showed positivity in 8 (21\%) of 38 follicular carcinoma cases. In nonmalignant lesions, the present study showed higher positivity for FA 3 cases $(60 \%)$ and adenomatous goiter 41 cases $(63.07 \%)$ when compared to de Matos et al. ${ }^{[2]}$ study, which showed $33.3 \%$ and $16.7 \%$, respectively. In terms of intensity for malignant lesions,

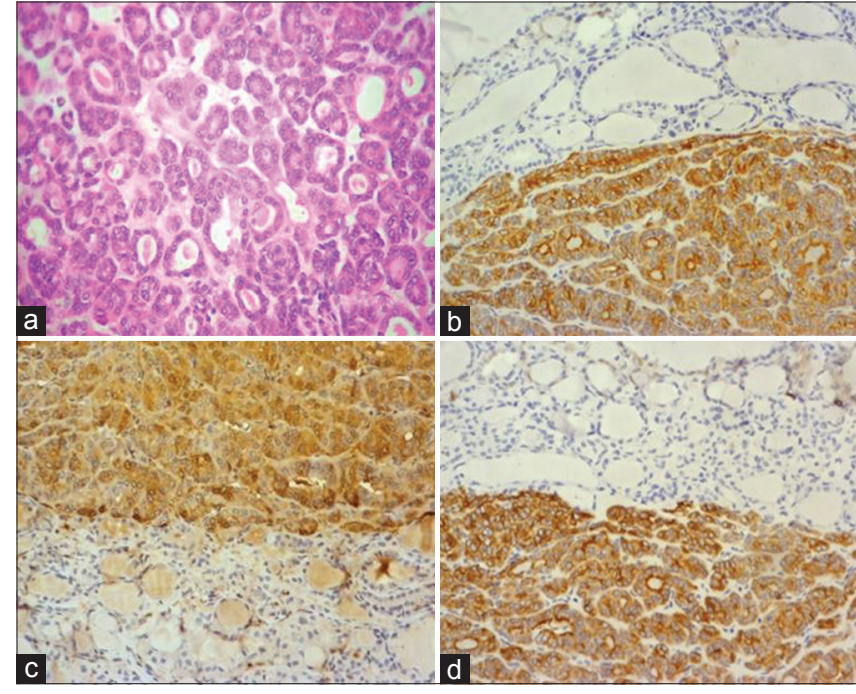

Figure 2: (a) Normo and microfollicles with nuclear features of papillary carcinoma in follicular variant of papillary carcinoma of thyroid $(H$ and $E, \times 10)$. (b) cytokeratin-19 showing diffuse intense cytoplasmic positivity for lesional cells but negative in adjacent adenomatous goiter ( $\times 20)$. (c) Galectin- 3 showing diffuse intense cytoplasmic positivity for lesional cells but negative in adjacent adenomatous goiter ( $\times 20)$. (d) Hector Battifora mesothelial-1 showing diffuse intense membranous and cytoplasmic positivity for lesional cells but negative in adjacent adenomatous goiter $(\times 20)$

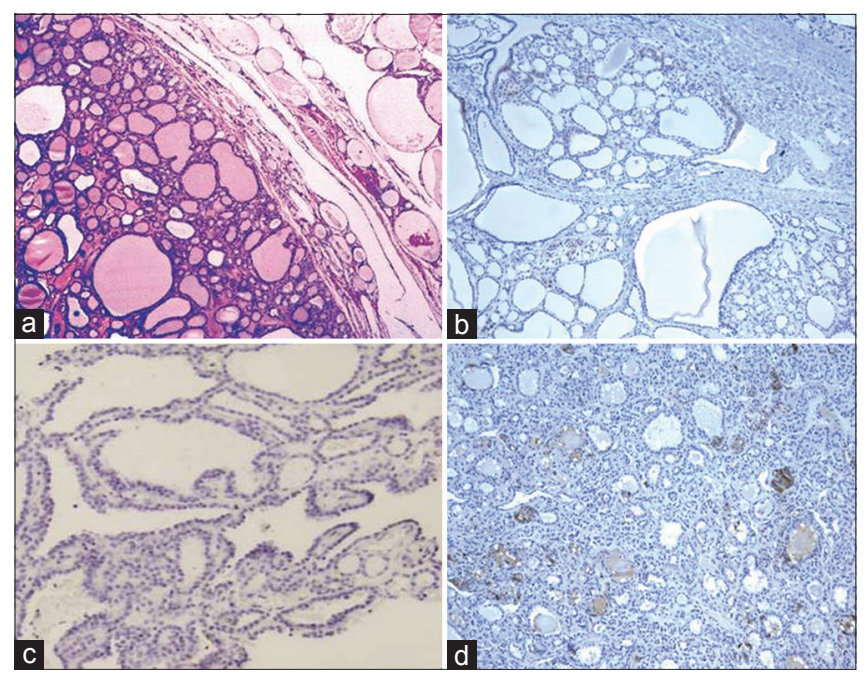

Figure 4: (a) Normo to colloid filled macrofollicles in adenomatous goiter ( $\mathrm{H}$ and $E, \times 4)$. (b) cytokeratin-19 showing negativity for follicular epithelial cells ( $\times 4)$. (c) Hector Battifora mesothelial-1 showing negativity for follicular epithelial cells $(\times 4)$. (d) Galectin-3 showing negativity for follicular epithelial cells but mild nonspecific positivity for colloid $(\times 4)$

moderate or strong positivity is seen in 42 cases (84\%) and negative or weak positivity in 8 cases $(16 \%)$, which is nearly similar to that of Scognamiglio et al. ${ }^{[14]}$ study 43 cases $(75.3 \%)$ and 14 cases $(24.7 \%)$, respectively. For 70 nonmalignant lesions, negative or weak staining was seen in 61 cases $(87.1 \%)$, which is much higher than Scognamiglio et al. ${ }^{[14]}$ study $(27.9 \%)$.

In the majority of PCT, we found strong and diffuse expression of CK-19. Our results are in concordance 
with the previous studies related to CK-19 expression in PCT. ${ }^{[15,16]}$ Beesley and McLaren ${ }^{[17]}$ point out (moderate/strong) positive CK-19 immunoreactivity in all PCT cases $(n=26)$ and weak/absent immunostaining in the majority of benign lesions and follicular carcinoma. Moon, ${ }^{[18]}$ in his study, showed that CK-19 is expressed only in PCT, being useful in differentiating FC from the

Table 4: Scores of different thyroid lesions in terms of percentage distribution and intensity for Hector Battifora mesothelial cell-1

\begin{tabular}{|c|c|c|c|c|c|c|c|c|c|}
\hline \multirow[t]{2}{*}{ Lesions } & \multirow[t]{2}{*}{$\begin{array}{c}\text { Total } \\
\text { cases }(n)\end{array}$} & \multirow[t]{2}{*}{$\begin{array}{l}\text { Negative/ } \\
\text { score } 0(n)\end{array}$} & \multicolumn{4}{|c|}{$\begin{array}{l}\text { Percentage } \\
\text { distribution }\end{array}$} & \multicolumn{3}{|c|}{ Intensity } \\
\hline & & & $1+$ & $2+$ & $3+$ & $4+$ & & $2+$ & $3+$ \\
\hline$A G$ & 65 & 45 & 18 & 2 & 0 & 0 & 18 & 2 & 0 \\
\hline FA & 5 & 1 & 2 & 0 & 1 & 1 & 1 & 2 & 1 \\
\hline $\begin{array}{l}\text { Conventional } \\
\text { PCT }\end{array}$ & 26 & 0 & 0 & 3 & 8 & 15 & 3 & 11 & 12 \\
\hline FVPCT & 17 & 2 & 0 & 0 & 6 & 9 & 0 & 7 & 8 \\
\hline НСРСТ & 3 & 2 & 0 & 0 & 1 & 0 & 1 & 0 & 0 \\
\hline $\begin{array}{l}\text { Microcarcinoma } \\
\text { PCT }\end{array}$ & 2 & 0 & 0 & 0 & 0 & 2 & 0 & 0 & 2 \\
\hline $\mathrm{FC}$ & 1 & 1 & 0 & 0 & 0 & 0 & 0 & 0 & 0 \\
\hline$A C$ & 1 & 1 & 0 & 0 & 0 & 0 & 0 & 0 & 0 \\
\hline
\end{tabular}

$\mathrm{AG}=$ Adenomatous goiter, $\mathrm{FA}=$ Follicular adenoma, $\mathrm{PCT}=$ Papillary carcinoma of thyroid, FVPCT $=$ Follicular variant of PCT, HCPCT $=$ Hurthle cell variant of $\mathrm{PCT}, \mathrm{FC}=$ Follicular carcinoma, $\mathrm{AC}=$ Anaplastic carcinoma

Table 5: Scores of different thyroid lesions in terms of percentage distribution and intensity for galectin-3

\begin{tabular}{|c|c|c|c|c|c|c|c|c|c|}
\hline \multirow[t]{2}{*}{ Lesions } & \multirow[t]{2}{*}{$\begin{array}{c}\text { Total } \\
\text { cases }(n)\end{array}$} & \multirow[t]{2}{*}{$\begin{array}{l}\text { Negative/ } \\
\text { score } 0(n)\end{array}$} & \multicolumn{4}{|c|}{$\begin{array}{l}\text { Percentage } \\
\text { distribution }\end{array}$} & \multicolumn{3}{|c|}{ Intensity } \\
\hline & & & $1+$ & $2+$ & $3+$ & $4+$ & $1+$ & $2+$ & $3+$ \\
\hline$\overline{A G}$ & 65 & 27 & 11 & 21 & 6 & 0 & 29 & 9 & 0 \\
\hline FA & 5 & 3 & 0 & 2 & 0 & 0 & 0 & 2 & 0 \\
\hline $\begin{array}{l}\text { Conventional } \\
\text { PCT }\end{array}$ & 26 & 0 & 1 & 1 & 5 & 19 & 0 & 8 & 18 \\
\hline FVPCT & 17 & 0 & 0 & 2 & 4 & 11 & 3 & 7 & 7 \\
\hline НСРСТ & 3 & 1 & 1 & 0 & 1 & 0 & 1 & 1 & 0 \\
\hline $\begin{array}{l}\text { Microcarcinoma } \\
\text { PCT }\end{array}$ & 2 & 0 & 0 & 0 & 0 & 2 & 0 & 1 & 1 \\
\hline $\mathrm{FC}$ & 1 & 1 & 0 & 0 & 0 & 0 & 0 & 0 & 0 \\
\hline $\mathrm{AC}$ & 1 & 0 & 0 & 0 & 0 & 1 & 0 & 0 & 1 \\
\hline
\end{tabular}

$\mathrm{AG}=$ Adenomatous goitre, $\mathrm{FA}=$ Follicular adenoma, $\mathrm{PCT}=$ Papillary carcinoma of thyroid, FVPCT $=$ Follicular variant of PCT, HCPCT $=$ Hurthle cell variant of $\mathrm{PCT}, \mathrm{FC}=$ Follicular carcinoma, $\mathrm{AC}=$ Anaplastic carcinoma follicular variant of PCT and PCT from the papillary areas in adenomatous goiter.

Kragsterman et al..$^{[19]}$ identified positive CK-19 expression in all (35 cases) examined PCT (occult, intra- and extrathyroid) and in 8 of 11 metastases, with variable immunoreactivity. Beesley and McLaren, ${ }^{[17]}$ in their study, observed that CK-19 appears to be useful in differentiating the follicular variant of PCT from FC and PCT from the papillary aspects in adenomatous Goitere. Stan V et al..$^{[20]}$ stated that CK-19 was very useful not only for the differentiation of benign and malignant papillary structure but also for the differential diagnosis of follicular PCT and Follicular carcinoma.

HBME-1: In 50 malignant cases, HBME-1 have shown positivity in 44 cases (88\%) which was similar to that of a study done by Scognamiglio et al. ${ }^{[14]} 51$ cases $(89.47 \%)$. In the 70 nonmalignant cases, HBME-1 was positive in 24 cases $(34.28 \%)$, which was much lesser when compared to Scognamiglio et al ${ }^{[14]}$ study $(66.66 \%)$. HBME-1 showed positivity in $44(91.66 \%)$ of 48 papillary carcinoma cases, similar to that of de Matos et al. ${ }^{[2]}(94 \%)$. It did not show positivity for both follicular and anaplastic carcinoma cases, while de Matos et al..$^{[2]}$ study showed positivity in 24 (63\%) of 38 follicular carcinoma cases. In nonmalignant lesions, the present study showed higher positivity for FA $(80 \%)$ when compared to de Matos et al. ${ }^{[2]}$ study $(55.6 \%)$, while in adenomatous goiter $(30.76 \%)$, positivity was almost similar (33.3\%). In terms of intensity for malignant lesions, moderate or strong positivity was seen in 40 cases ( $80 \%$ ) and negative or weak positivity in 10 cases $(20 \%)$, which was similar to that of Scognamiglio et al. ${ }^{[14]}$ study 49 cases ( $86 \%$ ) and 8 cases (14\%), respectively. For 70 nonmalignant lesions, negative or weak staining was seen in 65 cases $(92.85 \%)$, which was much higher than Scognamiglio et al..$^{[14]}$ study (60.4\%). HBME-1 has been reported to be one of the most promising markers according to de Matos et al..$^{[2]}$ and Prasad et al. ${ }^{[21]}$ In Park et al. ${ }^{[22]}$ study, HBME1 was expressed in $88 \%$ of follicular carcinomas, compared with the $64 \%$ positivity for galectin-3. However, HBME-1 was also expressed in $48.6 \%$ of FAs and $20.4 \%$ of nodular hyperplasias; these frequencies were similar to the present study.

Table 6: Sensitivity, specificity, positive predictive value, negative predictive value of individual and various combinations of immunohistochemistry markers in distinguishing malignant and nonmalignant lesions

\begin{tabular}{|c|c|c|c|c|}
\hline IHC markers & Sensitivity (\%) & Specificity (\%) & PPV (\%) & NPV (\%) \\
\hline$\overline{C K}-19$ & 84 & 95.71 & 93.33 & 89.33 \\
\hline HBME-1 & 82 & 97.14 & 95.35 & 88.31 \\
\hline Galectin-3 & 90 & 82.86 & 78.95 & 92.06 \\
\hline CK-19 + HBME-1 & 84 & 97 & 95.45 & 89.47 \\
\hline HBME-1 + galectin-3 & 82 & 97.14 & 95.74 & 93.15 \\
\hline CK-19 + galectin-3 & 84 & 95.71 & 93.75 & 93.06 \\
\hline CK-19 + HBME-1 + galectin-3 & 82 & 97.14 & 95.74 & 93.15 \\
\hline
\end{tabular}

PPV = Positive predictive value, NPV = Negative predictive value, IHC = Immunohistochemistry, CK-19= Cytokeratin-19, HBME-1 = Hector Battifora mesothelial cell-1 
Table 7: Comparison of all three immunohistochemistry markers in terms of sensitivity, specificity, positive predictive value, and negative predictive value found in our study with other studies

\begin{tabular}{|c|c|c|c|c|c|}
\hline IHC markers & Studies & Sensitivity (\%) & Specificity (\%) & PPV (\%) & NPV (\%) \\
\hline \multirow[t]{2}{*}{ CK-19 } & Park et al. ${ }^{[22]}$ & 90.3 & 83.1 & 92.5 & 78.7 \\
\hline & Present study & 84 & 95.71 & 93.33 & 89.33 \\
\hline \multirow[t]{2}{*}{ HBME-1 } & Park et al. & 91.3 & 68.5 & 87.0 & 77.2 \\
\hline & Present study & 82 & 97.14 & 95.35 & 88.31 \\
\hline \multirow[t]{2}{*}{ Galectin-3 } & Park et al. & 94.7 & 95.5 & 98.0 & 88.5 \\
\hline & Present study & 90 & 82.86 & 78.95 & 92.06 \\
\hline \multirow[t]{2}{*}{ HBME-1 + galectin-3 } & Park et al. & 85.9 & 100 & 100 & 75.4 \\
\hline & Present study & 82 & 97.14 & 95.74 & 93.15 \\
\hline \multirow[t]{2}{*}{ CK-19 + galectin-3 } & Park et al. & 86.4 & 100 & 100 & 76.1 \\
\hline & Present study & 84 & 95.71 & 93.15 & 93.06 \\
\hline \multirow[t]{2}{*}{ CK-19 + HBME-1 + galectin-3 } & Park et al. & 93.2 & 100 & 100 & 86.4 \\
\hline & Present study & 82 & 97.14 & 95.74 & 93.15 \\
\hline
\end{tabular}

$\mathrm{PPV}=$ Positive predictive value, NPV = Negative predictive value, IHC = Immunohistochemistry, CK = Cytokeratin, $\mathrm{HBME}-1=\mathrm{Hector}$ Battifora mesothelial cell-1

Galectin-3: In 50 malignant cases, galectin-3 have shown positivity in 48 cases (96\%) which was nearly similar to that of study done by Scognamiglio et al..$^{[14]}$ 50 cases $(87.71 \%)$. In the 70 nonmalignant cases, galectin-3 was positive in 45 cases $(64.28 \%$ ), which was also similar to that of Scognamiglio et al. study ${ }^{[14]}(58.33 \%)$. Galectin-3 showed positivity in $47(97.91 \%)$ of 48 papillary carcinoma cases, little higher than that of de Matos et al. (72.6\%). It showed positivity for the anaplastic carcinoma case but not for follicular carcinoma case, while de Matos et al.${ }^{[2]}$ study showed positivity in $8(21 \%)$ of 38 follicular carcinoma cases. In nonmalignant lesions, the present study showed (40\%) positivity for FA when compared to de Matos et al..$^{[2]}$ study (55.6\%). While in adenomatous goiter $(66.15 \%)$, positivity was higher to the study done by de Matos et al. ${ }^{[2]}$ (33.3\%).

In terms of intensity for malignant, moderate or strong positivity was seen in 44 cases (88\%) and negative or weak positivity in 6 cases $(12 \%)$, which was nearly similar to that of Scognamiglio et al..$^{[14]}$ study 44 cases $(77.2 \%)$ and 13 cases $(22.8 \%)$, respectively. For 70 nonmalignant lesions, negative or weak staining was seen in 64 cases $(91.42 \%)$, which was higher than that of Scognamiglio et al. ${ }^{[14]}$ study (70.9\%). In the Seçkin et al. ${ }^{[23]}$ study, the extent of staining by galectin-3 in PCT was significantly higher than in micro PCT and strong immunoreactivity was obtained in 12 PCT $(52.2 \%)$, while only 3 micro PCT (15.0\%) showed strong positivity.

Among the three markers [Table 7], galectin-3 has the highest sensitivity of $90 \%$ and NPV of $92.06 \%$ similar to that of Park et al. ${ }^{[22]}$ (94.7\% and $88.5 \%$, respectively). HBME- 1 has the highest specificity of $97.14 \%$ and PPV of 95.35\%, while galectin-3 had highest specificity (95.5\%) and PPV (98.0\%) in Park et al. ${ }^{[22]}$ study.

In combination of two different markers, sensitivity, specificity, PPV, and NPV are highest for
HBME-1 + galectin-3, that is, $82 \%, 97.14 \%$, 95.74\%, and $93.15 \%$, respectively, but in Park et al. ${ }^{[22]}$ study, combination of any 2 markers showed $100 \%$ specificity and $100 \%$ PPV but sensitivity and NPV was highest for CK-19 + galectin-3, that is, $86.4 \%$ and $76.1 \%$, respectively.

With combination of all three markers (CK-19 + HBME-1 + galectin-3), NPV (93.15\%) was higher than that of Park et al. ${ }^{[22]}$ study $(86.4 \%)$ but sensitivity (82\%), specificity (97.14\%), and PPV (95.74\%) are lower in the present study which are $93.2 \%, 100 \%$, and $100 \%$, respectively, in Park et al..$^{[22]}$ study.

\section{Conclusions}

- Total score of percentage distribution and intensity (4-7) for CK-19, HBME-1, and galectin-3 markers is higher in malignant lesions than in nonmalignant lesions

- Among the three markers, galectin-3 has the highest sensitivity of $90 \%$ and HBME-1 has the highest specificity of $97.14 \%$

- In combination of any two different markers, sensitivity, specificity, PPV, and NPV are highest for HBME- 1 + galectin-3, that is, $82 \%, 97.14 \%, 95.74 \%$, and $93.15 \%$, respectively

- With combination of all three markers (CK-19 + HBME-1 + galectin-3) sensitivity, specificity, PPV, and NPV are same as that of HBME-1 + galectin-3

- A panel of combined CK-19, HBME-1, and galectin-3 or HBME-1 + galectin-3 can increase the reliability of making a correct diagnosis in histopathologically difficult cases by differentiating them into malignant or nonmalignant lesions.

Financial support and sponsorship

This study was financially supported by Sri Balaji Arogya 
Vara Prasadini Scheme of Sri Venkateswara Institute of Medical Sciences, Tirupati, Andhra Pradesh, India.

\section{Conflicts of interest}

There are no conflicts of interest.

\section{References}

1. Papotti M, Rodriguez J, De Pompa R, Bartolazzi A, Rosai J. Galectin-3 and HBME-1 expression in well-differentiated thyroid tumors with follicular architecture of uncertain malignant potential. Mod Pathol 2005;18:541-6.

2. de Matos PS, Ferreira AP, de Oliveira Facuri F, Assumpção LV, Metze K, Ward LS, et al. Usefulness of HBME-1, cytokeratin 19 and galectin-3 immunostaining in the diagnosis of thyroid malignancy. Histopathology 2005;47:391-401.

3. Nasr MR, Mukhopadhyay S, Zhang S, Katzenstein AL. Immunohistochemical markers in diagnosis of papillary thyroid carcinoma: Utility of HBME1 combined with CK19 immunostaining. Mod Pathol 2006;19:1631-7.

4. Ozolins A, Narbuts Z, Strumfa I, Volanska G, Stepanovs K, Gardovskis J, et al. Immunohistochemical expression of HBME-1, E-cadherin, and CD56 in the differential diagnosis of thyroid nodules. Medicina (Kaunas) 2012;48:507-14.

5. Song Q, Wang D, Lou Y, Li C, Fang C, He X, et al. Diagnostic significance of CK19, TG, Ki67 and galectin-3 expression for papillary thyroid carcinoma in the Northeastern region of China. Diagn Pathol 2011;6:126.

6. Anidi AI, Ejeckam GC, Ojukwu J, Ezekwesili RA. Histological pattern of thyroid diseases in Enugu, Nigeria. East Afr Med J 1983;60:546-50.

7. Gitau W. An analysis of thyroid diseases seen at Kenyatta National Hospital. East Afr Med J 1975;52:564-70.

8. Ahmad J, Hashmi MA, Naveed IA, Hussain A, Amin D. Spectrum of malignancies in Faisalabad 1986-1990. Pak J Pathol 1992;3:103-10.

9. Lanier AP. Cancer incidence in Alaska natives. Comparison of two time periods, 1989-93 vs. 1969-73. Cancer 1998;83:1815-7.

10. Gole SG, Satyanarayana V, Gole GN, Ramamurti T, Hayath MS, Desh Pande AK. Profile of thyroid neoplasms with special focus on interesting cases: A hospital based 12 year longitudinal study. Int J Pathol 2013;14:528-37.

11. Thomas JO, Ogunbiyi JO. Thyroid cancers in Ibadan, Nigeria.
East Afr Med J 1995;72:231-3.

12. Khan AR, Hussain NK, Al-Saigh A, Malatani T, Sheikha AA. Pattern of cancer at Asir central hospital, Abha, Saudi Arabia. Ann Saudi Med 1991;11:285-8.

13. Woolner LB, Lemmon ML, Beahrs OH, Black BM, Keating FR Jr. Occult papillary carcinoma of the thyroid gland: A study of 140 cases observed in a 30-year period. J Clin Endocrinol Metab 1960;20:89-105.

14. Scognamiglio T, Hyjek E, Kao J, Chen YT. Diagnostic usefulness of HBME1, galectin-3, CK19, and CITED1 and evaluation of their expression in encapsulated lesions with questionable features of papillary thyroid carcinoma. Am J Clin Pathol 2006;126:700-8.

15. Cheung CC, Ezzat S, Freeman JL, Rosen IB, Asa SL. Immunohistochemical diagnosis of papillary thyroid carcinoma. Mod Pathol 2001;14:338-42.

16. Khurana KK, Truong LD, LiVolsi VA, Baloch ZW. Cytokeratin 19 immunolocalization in cell block preparation of thyroid aspirates. An adjunct to fine-needle aspiration diagnosis of papillary thyroid carcinoma. Arch Pathol Lab Med 2003;127:579-83.

17. Beesley MF, McLaren KM. Cytokeratin 19 and galectin-3 immunohistochemistry in the differential diagnosis of solitary thyroid nodules. Histopathology 2002;41:236-43.

18. Moon IP, Dae YK. Usefulness of galectin-3, cytokeratin 19, p53 and Ki-67 for the differential diagnosis of thyroid tumors. Korean J Pathol 2006;40:86-92.

19. Kragsterman B, Grimelius L, Wallin G, PetraW, Henry J. Cytokeratin 19 expression in papillary thyroid carcinoma. App Immunohistochem Mol Morphol 1999;7:181.

20. Stan V, Cornianu M, Lazar E, Dema A, Taban S, Golu I, et al. The value of ck19, ki-67 and p53 expression in the diagnosis of thyroid follicular neoplasms. TMJ 2011;62:59-64.

21. Prasad ML, Pellegata NS, Huang Y, Nagaraja HN, de la Chapelle A, Kloos RT, et al. Galectin-3, fibronectin-1, CITED-1, HBME1 and cytokeratin-19 immunohistochemistry is useful for the differential diagnosis of thyroid tumors. Mod Pathol 2005;18:48-57.

22. Park YJ, Kwak SH, Kim DC, Kim H, Choe G, Park DJ, et al. Diagnostic value of galectin-3, HBME-1, cytokeratin 19, high molecular weight cytokeratin, cyclin D1 and p27(kip1) in the differential diagnosis of thyroid nodules. J Korean Med Sci 2007;22:621-8.

23. Seçkin S, Karagece Ü. Expression of CK-19, cErbB2, galectin-3, and p53 in papillary thyroid carcinomas. Turk J Med Sci 2010;40:207-12. 